aspects reviewed included mode of delivery, birth weight, parity and if episiotomy was performed.

Results The incidence of OASI was $4.5 \%$ of all vaginal deliveries. There were 2 missed cases of OASI. Among the OASI cases, $32 \%$ laboured in the pool as analgesia or had a water birth. $62 \%$ had a normal vaginal delivery, $14 \%$ had a water birth and $24 \%$ had an instrumental delivery. Majority had a normal fetal weight (82\%). $88 \%$ has no episiotomy performed. Patients who had a water birth were more likely to sustain an OASI compared to normal vaginal delivery $(5.47 \%$ water births versus $3.66 \%$ normal delivery).

Conclusion The increased incidence of OASI in the unit may be due to the increased detection rate by obstetricians. Water birth is a potential risk factor for OASI but this area needs further research.

\section{PL.88 SYNTOCINON INFUSION: A PROSPECTIVE AUDIT AT ST JOHN'S HOSPITAL (NOV 2010 - APRIL 2011)}

doi:10.1136/archdischild-2013-303966.270

R Owusu-Ansah, S Coutts. St John's Hospital at Howden, Livingston, UK

Introduction The use of oxytocin infusion in the induction and augmentation of labour is an essential component of intra-partum care in obstetrics worldwide but can be associated with potentially serious complications. These complications include uterine hyperstimulation leading to abnormalities in the CTG, uterine rupture especially in labouring women with previous uterine scar, fluid overload and postpartum haemorrhage (prolonged usage). In the light of these potentially serious but avoidable complications, it is imperative to use it judiciously in accordance with clinical guidelines.

The Aim of this audit was to determine the adherence of the unit to the designated clinical guideline in the use of syntocinon infusion in labour and to ascertain and analyse the underlying reasons for the complete stoppage of infusion and the reduction in the dosage of infusions.

Results and Discussions Majority of patients on syntocinon infusion carried on to delivery without having syntocinon stopped $(99.08 \%)$ or reduced $(66.9 \%)$. A significant number though still had syntocinon reduced at least on 1 occasion (33.1\%).

The commonest reason for reducing rate of infusion was hyperstimulations (42/51), followed by other reasons such maternal distress, stopping to site epidural and "tissued venflon" representing $(12 / 51)$ and prolonged and persistent decelerations.

Conclusions The use of syntocinon infusion to augment or induce labour at St John's Hospital conforms to the established Pan-lothian guideline.

It is acceptable practise to reduce the rate of infusion when there is uterine hyperstimulation and to stop the infusion completely in the event of prolonged bradycardia and pathological CTG (NICE guideline).

\section{PL.89 FUNCTIONAL EFFECTS OF OESTRADIOL ON CYTOKINE RESPONSES OF HUMAN ECTOCERVICAL EPITHELIAL CELLS TO TOLL-LIKE RECEPTOR 2 AND 4 LIGANDS}

doi:10.1136/archdischild-2013-303966.271

BS Lashkari, DOC Anumba. University of Sheffield, Sheffield, UK

We have demonstrated that the pattern recognition toll-like receptors (TLR) $2 \& 4$ are upregulated during pregnancy in human cervical epithelium. We sought to determine whether oestradiol $\left(\mathrm{E}_{2}\right)$ alters the immunological responses of cultured human ecto-cervical epithelial cells (HECECs) to the ligands of TLR2 (peptidoglycan, PGN) and TLR4 (lipopolysaccharides, LPS).
Methods and Material Fresh ectocervical tissues were collected from hysterectomy specimens, epithelia isolated and cultured after collagenase and trypsin digestion, cell purity being validated by immunofluorescence. The expression of TLRs $2 \& 4$, and $\mathrm{E}_{2}$ receptor genes (ERs $\alpha \& \beta$ ) were demonstrated by flow cytometry and RTPCR respectively. HECECs were co-incubated with varying $\mathrm{E}_{2}$ concentrations $(0.1,1,10,100 \mathrm{nM})$ and PGN $(50 \mu \mathrm{g} / \mathrm{ml})$ or LPS $(100 \mathrm{ng} / \mathrm{ml})$ for $10 \mathrm{~min}, 2 \mathrm{hrs}$ and $18 \mathrm{hrs}$. Cytokines were assayed in supernatant fluid by Cyto-Bead Array.

Result In response to PGN, HECECs co-incubated with $\mathrm{E}_{2}$ released lower levels of IFN- $\gamma$, IL- 6 and IL-8, whilst after $18 \mathrm{hrs,} \mathrm{RANTES}$ expression increased to low $\mathrm{E} 2$ but decreased to high $\mathrm{E} 2$. In response to LPS, HECECs co-incubated with $\mathrm{E}_{2}$ demonstrated increased expression levels of IL-10, IL-12p70, RANTES and TNF $\alpha$ at $10 \mathrm{~min}$ and $2 \mathrm{hrs}$. IL- 6 and IL-8 levels increased at $2 \mathrm{hrs}$ but were suppressed or unchanged after $18 \mathrm{hrs}$. Markedly increased levels of RANTES were detected after $18 \mathrm{hrs}$, an effect obtunded by culturing HECECs in $\mathrm{E} 2$.

Discussion The complex immunomodulatory effects of $\mathrm{E}_{2}$ on cultured HECECs appear to vary with bacterial ligands and duration of exposure, suggesting direct non-genomic vs. genomic mechanisms. The resulting cytokine profiles may contribute to cervical remodelling during pregnancy.

\section{PL.90 DOCUMENTATION AND ASSESSMENT OF CONTINUOUS INTRAPARTUM ELECTRONIC FETAL HEART MONITORING}

doi:10.1136/archdischild-2013-303966.272

GA McLachlan, JL Cartmill, R Barclay. Altnage/vin Area Hospital, Western Trust, Londonderry, UK

Objectives To assess the effectiveness of an intrapartum CTG interpretation tool.

Background Intrapartum electronic fetal monitoring is used as a method of evaluating fetal well-being in labour. NICE guidance on the classification of intrapartum CTG's includes definitions and descriptions of individual fetal heart rate features and an overall grading system.

To improve documentation and reduce unnecessary interventions, a regional CTG evaluation tool (sticker) was introduced summarising this guidance.

Method Retrospective review of 101 intrapartum CTG stickers from 24 patient charts assessing standard of documentation and accuracy of CTG classification.

Results All 4 features were assessed and assigned an overall grading in $82 / 101$ (81\%) of cases, of which 74/82 (90\%) were concordant with independent analysis of overall grading. The CTG was upgraded from normal to suspicious in $3 / 82(4 \%)$ cases and downgraded from suspicious to normal in $5 / 82(6 \%)$ cases.

Original FHR documentation was incomplete in 19/101 (19\%) cases of which $8 / 19(42 \%)$ were independently graded as suspicious. Conclusions There was suboptimal completion of CTG stickers as only $81 \%(82 / 101)$ had all 4 features assessed and were assigned an overall grading.

In cases where the CTG stickers were fully completed, $91 \%(75 / 82)$ were independently graded as normal. Whereas, when the features were incomplete, $42 \%(8 / 19)$ were graded as suspicious following independent analysis which seemed to indicate a difficulty with interpretation and categorisation of decelerations and a reluctance of staff to commit to an overall grading if the CTG was not normal.

\section{PL.91 THE ETHICS DECISION CONCERNING PREMATURE NEWBORN: REFLECTIONS OF DOCTORS AND NURSES}

doi:10.1136/archdischild-2013-303966.273

EMB Silva, DM Silva. Polytechnic Institute of Viseu - CIDETS, Viseu, Portugal 